\title{
Does Engineering Attract or Repel Female Students Who Passionately Want
} to Help People?

\section{Dr. Angela R Bielefeldt, University of Colorado, Boulder}

Angela Bielefeldt, Ph.D., P.E., is a Professor in the Department of Civil, Environmental, \& Architectural Engineering at the University of Colorado Boulder. She has been on the faculty since 1996. She serves as the ABET Assessment Coordinator for the Department. Professor Bielefeldt teaches introductory courses for first year engineering students, senior capstone design, and environmental engineering specialty courses. She conducts engineering education research related to learning through service (LTS), social responsibility, sustainability, ethics, and globalization. 


\title{
Does Engineering Attract or Repel Female Students Who Passionately Want to Help People?
}

\begin{abstract}
Engineering promotes itself with messages that engineers help people, which may help attract female students. But will the curriculum that the students find in college reinforce this desire to help people through engineering... or will they decide that they are better able to pursue this goal through other avenues? This study explored the attitudes of female students at the end of their first semester in engineering in order to help answer this question. Students' reflective essays from first year introduction to civil engineering $(\mathrm{CE})$, environmental engineering (EvE), and architectural engineering (AE) courses were analyzed for content. The students were asked to discuss if they were interested in continuing to major in CE/EvE/AE and why or why not. A rubric was used to score the extent to which the students indicated that helping people was a motivation toward engineering; $35 \%$ of $\mathrm{CE}$ students and $32 \%$ of EvE students indicated that their primary motivation toward the major was the ability to help people. Engineers Without Borders (EWB) and first-year projects courses were beneficial in helping students understand the potential for engineering to positively impact people's lives. Of the students who indicated that their primary reason for selecting an engineering major was to help people, $50 \%$ persisted in $\mathrm{CE}$, $\mathrm{AE}$, or EvE disciplines, $11 \%$ transferred to other engineering disciplines, and $39 \%$ transferred to non-engineering disciplines. These students cited multiple reasons for plans to transfer out of engineering. Most of the students motivated to a career where they could help people maintained this vision for non-engineering disciplines. The study results indicate that serving society through engineering is a significant motivation for many female students and that further emphasis on the societal benefits of engineering in the first year might help to retain these students.
\end{abstract}

\section{Background}

Engineering is currently promoting itself with messages that engineers "improve people's lives in meaningful ways". ${ }^{20}$ This may help attract female students to engineering. A large number of studies have shown that women to a greater extent than men value work that helps and interacts with people, contributes to society, has a clear social purpose, and contributes to communal goals. ${ }^{5,7,11-17,19}$ This affinity may be due to female gender role ${ }^{4,6,8,14}$ or other factors. Studies have also shown that women are less willing to enter careers that they perceive will not allow them to fulfill these helping goals, such as science, technology, engineering, and mathematics careers. ${ }^{6,7}$

In general, people do not tend to perceive that engineering and technology jobs directly benefit people or society. ${ }^{20}$ For example, a 2009 study across five European countries found that $78 \%$ of female students indicated that helping other people was important in their future jobs, but only $52 \%$ believed that most information and communication (ICT) / computer engineering jobs involved this activity. ${ }^{9}$ The disconnect between women's value on helping society and their view that engineering will allow them to fulfill this goal may be a barrier to reaching gender parity in engineering, being problematic at both a university level and a contributor to the attrition of women out of engineering careers. 
However, it is clear that engineers generally perceive that they are helping society. A European study found that $100 \%$ of ICT professionals viewed ICT jobs as helping people. ${ }^{9}$ A study of STEM professionals in the private sector found that $63 \%$ of female scientists cited "...a desire to contribute to society's health and well-being..."10 as the main reason they chose their career. Similar findings in academia have shown that women are more likely than men to cite the ability to improve the world as the reason for choosing engineering. ${ }^{18}$ Simple interventions such as professionals discussing how their career helps people and society may help students to perceive the benefits of science / engineering to society and thereby increase their interest in these careers. $^{22}$

Males tend to have a more positive view of engineering's impacts on society than women. For example, in a fall 1998 study incoming first-year male engineering students had a more positive perception of how engineers contribute to society than female students at five institutions (with additional 10 institutions that were higher, but not statistically significant). ${ }^{1}$ The perception of engineers as contributing to the welfare of society was also more positive among first year male engineering students' in 2006, where male students averaged 4.66 compared to females at 4.29 (on a 6-point Likert scale where $4=$ agree a little bit, $5=$ agree, $6=$ strongly agree). $^{2}$

Differences in the perception of engineering as a profession that helps people, society, and the planet may also account for some of the wide disparity in the percentage of women in different engineering disciplines. The percentage of bachelors degrees awarded to women in 2011-2012 varied from a low of $8.5 \%$ in computer engineering to a high of $45.5 \%$ in environmental engineering. Zelezny et al. ${ }^{24}$ linked females more positive environmental attitudes and behaviors to "higher levels of socialization to be other oriented and socially responsible." The three majors that were targeted in the study reported in this manuscript are above average in the representation of women. Nationally, $18.9 \%$ of bachelor's degrees in engineering were awarded to women (2011-2012) compared to $20.6 \%$ in civil engineering (CE), $24.8 \%$ in architectural engineering $(\mathrm{AE})$, and $45.5 \%$ in environmental engineering $(\mathrm{EvE}){ }^{23}$

A spring 2013 study asked students in an open-ended question to describe their reasons for choosing their major. ${ }^{3}$ Responses were written in by 727 students, primarily mechanical, civil, and environmental engineering students in their first year, senior year, or graduate students at one of five institutions. The responses were coded using inductive methods and emergent themes examined. Impact on society was the second most frequent reason for choosing their major that was cited by female environmental and female civil engineering students $(42 \%$ and $27 \%$, respectively), and helping people was the third most cited reason $(22 \%$ and $13 \%$, respectively). While impact on society was the most frequently cited reason by male civil students $(24 \%)$ and second most frequently cited for male environmental engineering students $(23 \%)$, these percentages were lower than females. In contrast, these helping society or people reasons were not in the top three for either female or male mechanical engineering students. Interestingly, the percentages of women earning bachelors degrees in these disciplines follows the trends observed in the helping society/people responses of the students; only $12.4 \%$ of the bachelor's degrees in mechanical engineering were awarded to women compared to $20.6 \%$ for civil engineering and $45.5 \%$ for environmental engineering. ${ }^{23}$ 
A fall 2012 study including 1000 engineering students who were primarily mechanical, civil, and environmental engineering majors in their first year, senior year, or graduate school at five institutions asked students to rate the importance of eight attributes of their future careers, by distributing ten "points" into the different categories. ${ }^{3}$ On average women placed greater importance on helping people (average 2.6 points) than male students (average 2.1 points). More specifically, $52 \%$ of the women placed 3 or more points in the helping people attribute compared to only $24 \%$ of the males. The same survey included fifty 7 -point Likert questions related to social responsibility; the greatest differences between female and male students were in their responses to four questions that related to professional connectedness (on average 0.5 to 0.67 higher): it is important to me personally to have a career that involves helping people; the needs of society have no effect on my choice to pursue engineering as a career (reverse scored), I feel called by the needs of society to pursue a career in engineering; I think it is important to use my engineering to serve others. This clearly shows that "a desire to align one's career with personal desires to help society is more important to female engineering students than male students." 3

But somewhat troubling, this same study found that female seniors compared to first year female students had a lower "belief in their ability to help others, feelings of personal obligation to help others, beliefs of the engineering professions' ability to help society, and beliefs of professional obligation to help others." 3 One potential reason for these less positive attitudes among senior females might be due to the attrition of females with high social responsibility out of engineering. However, this is only speculative because it was not a longitudinal study.

Building on previous research, the goal for this research was to explore the attitudes of first-year female engineering students toward helping people. Did the curriculum that the students experienced in their first semester in college reinforce their desire to help people through engineering? Or did some students decide that they were better able to pursue this goal through other avenues?

\section{Methods}

This qualitative study was conducted using content analysis of reflective essays that were written by female students at a large public university. The students were enrolled in a first year introduction to civil engineering (CE), environmental engineering (EvE), or architectural engineering (AE) course. The majority of the students in each course were in their first semester of college, had declared their major in the named discipline, and therefore were required to take the course. From 2008 to 2011 these courses were 1 credit. In 2012 the course was increased to 2 credits. These courses were designed with the following learning objectives:

1. describe $\mathrm{CE} / \mathrm{EvE} / \mathrm{AE}$, what you may do as a $\mathrm{C} / \mathrm{Ev} / \mathrm{A}$ engineer, and the skills required for these engineering disciplines

2. explain the importance of professional licensure (PE)

3. understand why the information you are learning in your other classes is relevant engineering

4. apply the professional codes of engineering ethics to evaluate situations you may encounter in your career

5. define sustainability, describe its importance to engineering, and identify aspects of sustainability in $\mathrm{CE} / \mathrm{EvE} / \mathrm{AE}$ projects 
The students worked to achieve these learning goals facilitated by lectures, guest speakers from industry, reading assignments, and seven course homework assignments. The final assignment of the semester required students to write reflective essays. The assignment asked students to reflect on their definition of $\mathrm{CE} / \mathrm{EvE} / \mathrm{AE}$, if they were interested in continuing to major in $\mathrm{CE} / \mathrm{EvE} / \mathrm{AE}$, and why. Students were prompted to discuss personal experiences prior to college, content in the first year $\mathrm{CE} / \mathrm{EvE} / \mathrm{AE}$ course, and other college courses that impacted this decision. Students were also instructed to "Cite specific aspects of CE/EvE/AE and being a $\mathrm{C} / \mathrm{Ev} / \mathrm{A}$ engineer that appeal to you and do not appeal to you."

The essays were generally about two pages long. The assignment was worth ten percent of the overall course grade. It was graded on whether or not the students fully answered each question, not based on their specific responses (such as the level of correctness of their definition of the discipline). For this research, essays from the CE course were explored from 2008 to 2012; essays from the EvE course from 2010 were explored (the final year that reflective essays were available); essays from AE course in 2012 were explored (in no other years did the AE students write reflective essays). The wide range of years for $\mathrm{CE}$ was used in order to have a reasonably high number of essays from female students. The percentage of female students enrolled in these courses were $14-23 \%$ for CE (average 18\%), 45\% for EvE, and 34\% for AE.

In fall 2013 a rubric was developed to rate the extent to which the students indicated that helping people was a motivation toward engineering. Then each of the female student essays were read and scored, and quotes that caused the rating level were noted. Quotes from the student essays are provided in the results section in italicized text. In some cases bold has been added to draw attention to particular statements within the longer quotes, but that emphasis was added by the researcher and was not present in the student essay itself. The self-stated intent of the student to continue in their major or change major was noted, as well as their actual major in September 2013. Because the research focused on female students, essays from the male students were not scored using the rubric nor explored for themes related to helping people. The research could not be extended to explore other engineering majors because similar reflective essays were not written by students in other first year introductory courses.

\section{Results}

The reflective essays demonstrated a wide range in the extent to which students considered that $\mathrm{CE} / \mathrm{AE} / \mathrm{EvE}$ made a difference in people's lives (Table 1). On average, architectural engineering students scored lower on the "engineers help people" rubric than civil or environmental engineering students. Half of the AE students failed to mention this positive impact of AE on society or people, even in their definitions of the profession. In contrast, almost all of the $\mathrm{CE}$ and EvE students at least indicated that these disciplines help people and/or society. In some of the EvE essays this sometimes seemed to be an inadvertent consequence of benefitting the environment, or humans were merely part of having a "better world for all species." 
Table 1. Percentage of Female Student Essays that Scored at Each Level of the Rubric

\begin{tabular}{|lcc|cccc|}
\hline & & & \multicolumn{4}{c|}{ Percentage of Female Students } \\
Course & $\begin{array}{c}\text { Student } \\
\text { N }\end{array}$ & $\begin{array}{c}\text { Average } \\
\text { Rubric } \\
\text { Score }\end{array}$ & $\begin{array}{c}\text { mention } \\
\text { social } \\
\text { benefits }\end{array}$ & $\begin{array}{c}\text { Mentioned that engineers } \\
\text { help people but unclear } \\
\text { that it is personally } \\
\text { important }\end{array}$ & $\begin{array}{c}\text { Important that } \\
\text { engineering } \\
\text { can help } \\
\text { people }\end{array}$ & $\begin{array}{c}\text { Primary } \\
\text { motivation } \\
\text { to help } \\
\text { people }\end{array}$ \\
\hline CE & 46 & 1.99 & 7 & 24 & 35 & 35 \\
AE & 12 & 0.91 & 50 & 17 & 25 & 8 \\
EvE & 34 & 2.02 & 3 & 24 & 41 & 32 \\
\hline
\end{tabular}

Examples of student statements that reflect level 1 of the rubric are:

Civil engineering works to better our society... and have a common goal of providing for the human race and betterment of the world we live in.

Architectural engineering is the use of math and science by studying them and practice them with other materials to safely build and construct a good environment for humans.

Environmental Engineering is branch of engineering that focuses on protecting human health and wellbeing.

About one-third of the students indicated that the ability of these disciplines to help people was a factor, among others, that they liked about the discipline. Examples from the student essays that illustrate level 2 of the rubric are:

The aspects of Environmental Engineering that do appeal to me are improving the environment, helping people, and the possibility of working in a foreign company.

The thing that appeals to me the most is the fact that I'd have the opportunity to see a project turn from nothing to a complete structure... and make an obvious impact in a community.

About one third of the $\mathrm{CE}$ and EvE students indicated that their primarily reason for selecting the major was to make a positive difference in people's lives. Examples of quotes for level 3 on the rubric are provided below:

The thing that appeals most to me about civil engineering is the fact that I will be able to help people.

I would like to travel to a third world country and help improve their quality of life and water supply. This makes me want to become an engineer so that I can help keep the world to the best of its ability. 
Before I came to college there were two things I was sure of and one was that I wanted to give back to others.

Prior to [college] I had always wanted to work in the Peace Corps. Civil engineering mainly appeals to me because of the amount of people that will be benefitted from each project.

The most important aspect of being an environmental engineer, in my opinion, is serving the public and making our surrounding environment a healthier and safer place that is beneficial for not only humans, but for the entire ecological system.

Environmental engineers are enlisted to serve the public and the environment as best they can, and this is something that motivates me more than anything. I know I want to spend my life helping people and helping protect and preserve the environment.

The majors of the students who were most motivated into engineering by the desire to serve others (level 3 on the rubric) were cataloged in fall 2013 (Table 2). It was found that only half of these students remained in $\mathrm{CE} / \mathrm{EvE} / \mathrm{AE}$ or transferred to one of these three closely related disciplines (civil, environmental, or architectural engineering). The highest within-major retention was for EvE majors (7 of 11 or $64 \%$ ), compared to $44 \% \mathrm{CE}$ and $0 \% \mathrm{AE}$. This may reflect differences in the extent to which these students were satisfied by the prospect of serving people through engineering. But a confounding factor is that these numbers represent retention at different points in college. Some of the CE students from 2008 had graduated from college; in contrast, the $2012 \mathrm{AE}$ and CE students were only in their sophomore year and their major could still change. The overall retention of these students within engineering overall $(61 \%)$ is similar to the retention of female students within the College of Engineering at the institution.

Table 2. Number of the Female Students Who Were Motivated into Engineering by a Desire to Help People in Various Majors, September 2013 (number of students reported for each major, and overall percentage of the students across the three majors)

\begin{tabular}{|lccc|}
\hline Course & $\begin{array}{c}\text { Persisted in CE, AE, } \\
\text { and/or EvE }\end{array}$ & $\begin{array}{c}\text { Other College of } \\
\text { Engineering discipline }\end{array}$ & Non-engineering discipline \\
\hline $\mathrm{CE}$ & 7 & 2 & 7 \\
$\mathrm{AE}$ & 0 & 0 & 1 \\
$\mathrm{EvE}$ & 7 & 1 & 3 \\
\hline All & $50 \%$ & $11 \%$ & $39 \%$ \\
\hline
\end{tabular}

Some individuals already stated an intent to leave engineering in their reflective essays at the end of the semester. Some of these reasons related to their goals to help people. But typically, an unfulfilled need to help people wasn't the sole reason that individuals described as moving them away from engineering. First are two examples of students very passionate about helping people, but engineering doesn't appear to sufficiently meet this goal:

I enjoy helping others; that is the main reason why I considered engineering. I have learned that engineering does not fulfill this need enough for me. I want to emphasize my studies in sports medicine or physical therapy and rehabilitation. When planning my course schedule, I also saw a very strict and narrow path that students must follow in order to receive an 
engineering degree. I came to college to explore a different view on life, receive a small taste of the real world, and to find my true self. I want to take classes that were not offered to me in high school, and I would not be able to do this as an engineer. CE1

I am a very passionate person that enjoys directly helping people. I am thankful for my therapist and psychologist after falling back in to depression, and they have influenced me to someday be like them, so I can help others when they are in the same situation as me... AE1

Some students with a passion for helping people were lost from engineering not really because they didn't feel that engineering would meet this goal, but other factors. One student seemed to have goals that would be met with an engineering degree (e.g. rebuilding countries after wars) but seemed put off by the work load and curriculum:

...last year, I came to the conclusion that I should become a civil engineer. First, I thought about what would enable me to fulfill my lifelong goal and passion to make the world a better place. Civil engineering seemed like a great option. I could ... build schools, hospitals, bridges, and other structures in places that need them but do not have the means to construct them themselves. It would enable me travel and see the world as well. Engineering also had monetary perks; a guaranteed job with a sixty thousand salary right out of college would pay off [university] debts after a few years. After that I could begin what I really wanted to do without having to worry about debts and the lack of income associated with helping poor villages elsewhere. Then, I thought back on my life and remembered playing with legos and Lincoln logs and even using drills and nails once to make some primitive shelves for the basement with my dad (this type of simple building in civil engineering still appeals to me - no calculus needed!). I really enjoyed doing those activities and I was actually good at calculus and science in high school, so naturally, it made sense.

However, after experiencing almost a full semester of torture and agony with a bunch of smart, fast learning students interested in pursuing the same degree as me, I've changed my mind. The only engineering class I am in that I actually enjoy is the Engineering Projects class; I love building and cutting stuff in the machine shop. Conversely, I don't want to do three hours of calculus for every hour of class time and I don't want to learn about electron shells and subshells. I also found that I enjoy doing my philosophy homework and writing papers and reading for that class more than any of my engineering classes. I'm changing my major to political science and possibly with a minor in international affairs. This way I will be learning about the government and contemporary issues in class as opposed to trying to make time for it after all my engineering homework is done. I plan to work with nonprofit organizations and to work for United Nations reform. In addition, I would really like to play a key role in the rebuilding of Afghanistan, Iraq, and whatever other wars that may come about and cause destruction and displacement in this lifetime. If that doesn't work out I'd be happy doing work anywhere that helps disadvantaged people. CE2

Another student voiced concern about the constrained nature of the curriculum for engineering; this turned her away from engineering as opposed to the attributes of an engineering career or helping people:

I have decided that I do not want to be a Civil Engineer. In high school, I was good at and enjoyed both math \& physics and reading \& writing, but decided that degree I wanted to 
pursue was engineering. Now that I have taken a semester of Engineering classes, and looked at the schedule I have planned for the next four years, I can see that this was not the right decision for me. I still enjoy math and physics, but the education I would get with an Engineering track is very narrow and specific. I want a broader education, with English and history, where I actually get to choose some of my classes. I did enjoy the other courses I took this semester, and I will always enjoy math and physics, but I didn't get to take the type of Humanities classes I wanted to. [The material in this class] showed me what my life as an engineer could be like, and it was actually quite appealing. However, although I believe I could be a successful engineer, I think I would miss out on other things I could be learning.

If I were to continue to get my engineering degree, I would like to do something like the Engineers Without Borders are doing, and help others with my degree. The opportunities to travel as an engineer are numerous, which is also appealing. The things that don't appeal to me about the Civil Engineering profession are ... not getting a worldly education. Although I know that many engineering jobs vary from day to day, and many (especially in the construction field) involve working outside, I can't sacrifice my desire to learn about the world. CE3

The difficulty of the courses was also daunting to some students. This was mentioned in one of the previous examples (CE2: "a full semester of torture and agony") and by another student:

After this semester, I do not want to pursue civil engineering anymore. I still think that civil engineering is very appealing, however, I have chosen to go in a different direction... and have decided to pursue a career in secondary education. I've always been unsure of what I wanted to do as a career, but I've always enjoyed helping other people.... There were parts of this course that made me really wanted to pursue a career in civil engineering, and other parts that weren't so appealing. This course left me in a neutral place. It was my other classes that had a huge affect on my final decision ... a heavy load of difficult classes. This kind of semester is what I'd be looking at for the rest of my college career, and I was incredibly stressed out, so that ultimately had the most influence on my decision to go in a different direction. CE4

An example of another perspective where an altruistically motivated student left their first semester uncertain about engineering is:

At this point, I am unsure of whether or not I would like to continue with environmental engineering; before college I was absolutely sure this is what I wanted to do for a living because I was very passionate about it. What appeals to me about environmental engineering is the ability to make a positive difference on the world by helping the environment and that in turn should lead to a better quality of life. Studying the environment is also something that really interests me, it is made up of so many complicated systems, everything affects everything else; there is literally endless amounts of knowledge to be gained when studying environmental systems. I pride myself on what I know about the world around us. What I do not like about environmental engineering is consulting. I don't want to become a consultant for an oil and energy company or for a manufacturer like Proctor and Gamble, where I would be working for big business and not so much for the public. EvE1

Some students would tend to focus on elements of the profession that they liked and acknowledge other areas that they didn't, but were aware that they could select a career path with their engineering major that met their goals. The student EvE1 seemed to focus more on 
negative elements and seemed to have a weak sense that she controlled what she would do with her degree.

Some students were motivated to remain in engineering due to their desire to help people and positively impact society, despite some negatives. For example:

I definitely still intend to become an Environmental Engineer. I first decided this as my major when I was in Cambodia and Thailand junior year of high school. It became so clear to me that I want to help these kinds of people and their communities rather than anything else. [The guest speaker] really inspired me and made my dream more realistic in my mind. He really has done wonderful things with his degree and that's what I strive to do. My other courses have made me change my mind throughout the semester just by frustration. My Calculus 2 exam two killed me and really had me down on myself but my last midterm was spectacular so I believe this semester has taught me to just stay strong and not let one grade get me down and that eventually I will have the privilege of calling myself an Environmental Engineer.

There are many aspects in the field of Environmental Engineering that intrigue me as well as turn me off from the profession. One of the main reasons that I know this career path is right for me is because I love to help people and this is a great way to do that for people who otherwise would have no assistance at all. This major is also a globally recognized degree and would allow me to work in many different countries all throughout the world. The fact that I will be able to travel around the world and help the less fortunate people is enough incentive for me to want to continue on this demanding journey.... Although I truly love the profession, with all love comes a little hate. I don't like how right now there are not a lot of woman in this kind of work force. This needs to change drastically as women are able to think differently than men and are able to give just enough, if not even more, input on ideas and thoughts. Right now, I don't appreciate the level of difficulty that the schooling is, but I know this hard work and dedication will pay off in the end.... EvE2

Overall, it is clear that a complex set of factors contributed to a student's decision to persist in engineering or leave.

For some students, a passion to help people is a primary factor motivating them toward engineering, so allowing them to see this ability to help people through their engineering courses might help retain these students. A number of students discussed Engineers Without Borders (EWB) and their first year projects course (Table 3). A higher percentage of the female EvE students and students most motivated by the helping people aspects of engineering (level 3 on the rubric) discussed EWB.

Table 3. Percentage of Essays that Discussed EWB or First Year Projects Course

\begin{tabular}{|lcc|}
\hline Female Students in: & EWB & First Year Projects Course \\
\hline CE course & $13 / 46=28 \%$ & $20 / 46=43 \%$ \\
AE course & $2 / 12=17 \%$ & $0 / 12=0 \%$ \\
EvE course & $16 / 34=47 \%$ & $17 / 34=50 \%$ \\
CE/AE/EvE course (all) & $31 / 92=34 \%$ & $37 / 92=40 \%$ \\
Level 3 of the helping rubric & $14 / 28=50 \%$ & $12 / 28=43 \%$ \\
\hline
\end{tabular}


Examples of student statements about EWB are given below. However, since EWB is an extracurricular activity, the opportunity to participate in EWB alone is likely insufficient to drive retention.

Another experience I have had was getting the chance to work with Engineers Without Boarders in my high school engineering elective. My engineering class was asked to help them come up with a solution to creating a water distillation system they could produce in South America. That's when the excitement came in, how do you create something that is going to affect people's heath, be kind to the environment, and only using the materials they had available to them. EvE3

\section{CE5}

Engineers Without Borders is one of the main reasons I decided to study Engineering.

Hands-on class projects can reinforce the benefits of engineering toward helping people. $\mathrm{CV}$ and EvE students are encouraged to take a first-year engineering projects class in the first semester, while AE students are encouraged to take the projects course in the second semester, which accounts for the fact that none of the AE students discussed the projects course (as shown in Table 3). About half of the CV and EvE students mentioned the projects course. One student wrote:

My Engineering Projects class this semester also reassured me of my choice in environmental engineering. The project for our section was to design a pilot scale water disinfection system aimed for use in developing countries. At times, this class could be discouraging if the project design wasn't coming together or there was a problem with the team, but the result was the most encouraging part. At the end of the semester, knowing we designed and built something that could potentially be used to help people was the most encouragement I could ask for this semester. EvE4

The project the student referred to was contextualized based on helping people. Some other sections of the same course were service-learning (SL) projects that directly benefitted an individual or community.

My Engineering Projects Course (GEEN 1400), has furthered my wanting to join this every-growing field. I realized that I love working on and leading projects for the betterment of society and the environment. My team created a wheel-chair broom for a man with Cerebral Palsy. I really felt like I made a difference in a man's life, and it felt good. I want to make a worldly difference now. EvE5

During this semester I took a client based projects class. I built a hot wheels racecar trackfor a daycare center completely from scratch. When we showed it at the expo all of the kids had so much fun playing with it and it motivated me a lot. Seeing something I helped build in a city would make me so proud and happy, I couldn't imagine pursuing a career that did not have that kind of fulfillment. I do not think that I would be able to continue such rigorous studies if I did not believe I would enjoy my career when I finished. Also my projects class really taught me how you much a good engineer needs to be able to interact with people. I have always 
been rather outgoing and I do not think I could work in an atmosphere where I did not get to talk to a client or ask them questions about what they wanted. CE6

Not all of the comments related to the projects course were related to societal benefits nor were they all positive; for example:

I was enrolled in engineering projects this semester (GEEN 1400) and it was an extremely difficult course for me. The projects we worked on were frustrating to me. When they didn't work I couldn't get the motivation to rethink the problem and work again. I don't enjoy the building process, and the redesign and rebuilding that comes with it. This course in particular reaffirmed my decision to switch majors. CE7

Another strategy is to bring working professional guest speakers who can reinforce the benefits of engineering toward helping people. The guest speakers in the introductory $\mathrm{CE} / \mathrm{EvE} / \mathrm{AE}$ courses were not explicitly instructed to talk about the societal impacts of their work, but this sometimes came through. Some example student statements are:

The one speaker that interested me the most was [] and her works with Engineers without Borders. Throughout my travels to developing countries I witnessed the hardships that the natives had to deal with just to live a simple life. [The speaker's] work in Peru helping build solar-powered public water system is amazing and inspiring. The part about this job that appeals to me is using my engineering degree for a useful and helpful way to help the people in need the most. Also, I love traveling and experiencing other cultures. EvE6

During the guest speaker presentations, there were a few interesting things that I learned.... I also learned that there is a lot of potential for charity work in other countries in Environmental Engineering positions, which would be a rewarding opportunity to pursue. EvE7

Other elements of the introductory $\mathrm{CE} / \mathrm{EvE} / \mathrm{AE}$ course also reinforced societal benefits. Within the ethics module, students explored "exemplars" including Fred Cuny, an engineer who used his expertise toward disaster relief. ${ }^{21}$ The courses also included a sustainability module, where social benefits of sustainable engineering were discussed. An example of this impact is:

I knew that civil engineers focused upon designing infrastructure for society, but I did not know the importance that sustainability in the role of a civil engineer. I have [be] come familiar with the fact that this type of engineering has both a responsibility to protect the community and the environment. CE8

My definition [of CE] has changed during the semester with the additional recognition of how Civil Engineers act in the profession. I have learned that when working on a Civil Engineering project, the most important thing that is focused on is safety. The well-being of society strongly depends on its safety, so that is what's stressed the most in any project. The second most important thing focused on is sustainability. This ranges from economic sustainability to environmental sustainability to social. All three pillars of sustainability are equally important to any project and are very important in defining the profession. CE9 


\section{Conclusions}

About $30 \%$ of female first year CE and EvE students were pursuing majors in engineering primarily in order to help people and society. An additional 30 to $40 \%$ of female CE, AE, and EvE first year students indicated that it was important that engineering can help people. Of the students who indicated that they had selected engineering primarily to help others, about $40 \%$ left engineering. Some of these students indicated that they felt there were other majors more suited to their helping people goals. In general, a complex array of factors were cited by the students as detractors from engineering, often including the constrained nature of the curriculum and/or difficult course requirements. Service-learning projects in required courses, extracurricular service opportunities (such as Engineers Without Borders), and professionals who discuss helping people via their work may help to educate students about the benefits of engineering. These types of activities may help retain in engineering female students who are passionate about helping people and serving society. This motivation may help these students to persist through other perceived detractors. Both the engineering profession and society at large will benefit if a growing number of individuals with strong "people serving" goals become engineers.

\section{References}

1. Besterfield-Sacre, M., M. Moreno, L.J. Shuman, C.J. Atman. 2001. Gender and ethnicity differences in freshmen engineering student attitudes: a cross-institutional study. Journal of Engineering Education, 90 (4), 477-489.

2. Bielefeldt, A.R. 2008. Cultural Competency Assessment. American Society for Engineering Education Annual Conference. Paper AC 2008-2313.

3. Canney, N.E. 2013. Assessing Engineering Students' Understanding of Personal and Professional Social Responsibility. Ph.D. Dissertation. Department of Civil, Environmental, \& Architectural Engineering. University of Colorado Boulder.

4. Cejka, M.A., A.H. Eagly 1999. Gender-stereotypic images of occupations correspond to the sex segregation of employment. Personality \& Social Psychology Bulletin, April.

5. Cerinsek, G., T. Hribar, N. Glodez, S. Dolinsek. 2013. Which are my future career priorities and what influenced my choice of studying science, technology, engineering or mathematics? Some insights on educational choice - case of Slovenia. International Journal of Science Education. 35 (17), 2999-3025.

6. Diekman, A.B., E.R. Brown, A.M. Johnston, E.K. Clark. 2010. Seeking Congruity Between Goals and Roles: A New Look at Why Women Opt Out of Science, Technology, Engineering and Mathematics Careers. Psychological Science, 21 (8), 1051-1057.

7. Diekman, A.B., E.K. Clark, A.M. Johnston, E.R. Brown, M. Steinberg. 2011. Malleability in communal goals and beliefs influences attraction to STEM careers: evidence for a goal congruity perspective. Journal of Personality and Social Psychology. 17 pp. doi: 10.1037/a0025199 
8. Evans, C.D., A.B. Diekman. 2009. On motivated role selection: gender beliefs, distant goals, and career interest. Psychology of Women Quarterly, 33, 235-249.

9. Gras-Velazquex, A., A. Joyce, M. Debry. 2009. Women and ICT: Why are girls still not attracted to ICT studies and careers? White Paper. European Schoolnet (EUN Partnership AIBSL), Brussels, Belguim. http://eskills.eun.org

10. Hewlett, S. A., Luce, C. B., Servon, L. J., Sherbin, L., Shiller, P., Sosnovich, E., et al. 2008. The Athena Report: Reversing the Brain Drain in Science, Engineering, and Technology. Cambridge, MA: Harvard Business School Publishing Corporation.

11. Hill, C., C. Corbett, A. St. Rose. 2010. Why So Few? Women in Science, Technology, Engineering and Mathematics. American Association of University Women (AAUW). Washington D.C.

12. Jones, M.G., A. Howe, M.J. Rua. 2000. Gender Differences in Students' Experiences, Interests, and Attitudes toward Science and Scientists. Science Education. 84 (2), 180-192.

13. Jozefowicz, D.M., B.L. Barber, J.S. Eccles. 1993. Adolescent work related values and beliefs: gender differences and relation to occupational aspirations. Paper presented at the Biennial Meeting of the Society for Research on Child Development. New Orleans, LA, March 28. 22 pp.

14. Konrad, A. M., Ritchie, J. E., Jr., Lieb, P., \& Corrigall, E. (2000). Sex differences and similarities in job attribute preferences: A meta-analysis. Psychological Bulletin, 126(4), 593-641.

15. Lippa, R. 1998. Gender-related individual differences and the structure of vocational interests: the importance of the people-things dimension. Journal of Personality and Social Psychology. 74 (4), 996-1009.

16. Lubinski, D., \& Benbow, C. P. (1992). Gender differences in abilities and preferences among the gifted: Implications for the math-science pipeline. Current Directions in Psychological Science, 1(2), 61-66.

17. Margolis, J., Fisher, A., \& Miller, F. (1999). Caring about connections: Gender and computing. IEEE Technology and Society Magazine, Winter. 13-20.

18. Meyers, K., B. Mertz. 2011. A Large Scale Analysis of First-Year Engineering Student Essays on Engineering Interests. American Society for Engineering Education Annual Conference \& Exposition (pp. 1-16). San Antonio, TX: ASEE.

19. Morgan, C., J.D. Isaac, C. Sansone. 2001. The role of interest in understanding the career choices of female and male college students. Sex Roles. 44 (5/6), 295-320.

20. NAE (National Academy of Engineering. 2008. Changing the Conversation: Messages for Improving Public Understanding of Engineering. National Academies Press. Washington D.C.

21. NAE. 2006. "Fred Cuny (1944-1995) -Disaster Relief Innovator" Online Ethics Center for Engineering 6/6/2006 National Academy of Engineering Accessed: Wednesday, November 20, 2013

$<$ www.onlineethics.org/Topics/ProfPractice/Exemplars/BehavingWell/cunyintro

22. Weisgram, E.S., R.S. Bigler. 2006. Girls and science careers: the role of altruistic values and attitudes about scientific tasks. Journal of Applied Developmental Psychology. 27, 326-348.

23. Yoder, B.L. 2012. Engineering By the Numbers. In: 2012 ASEE Profiles of Engineering and Engineering Technology Colleges, ASEE, Washington D.C. pp. 11-47.

24. Zelezny, L.C., P-P. Chua, C. Aldrich. 2000. Elaborating on gender differences in environmentalism. Journal of Social Issues, 56 (3), 443-457. 